\title{
Transition from the Triple Helix to N-Tuple Helices? An interview with Elias G. Carayannis and David F. J. Campbell
}

\author{
Han Woo Park
}

Received: 2 July 2013/Published online: 14 September 2013

(C) Akadémiai Kiadó, Budapest, Hungary 2013

\begin{abstract}
Given the widespread use of many digitalized communication channels, knowledge production activities have rapidly become interrelated. As the term "network society" implies, knowledge-based innovation systems have been built mainly on the mediated social infrastructure, which has lead to the emergence of the N-Tuple Helix model. I wish to contribute to this special issue by offering an interview with Prof. Dr. Elias G. Carayannis and Dr. David F. J. Campbell, the two co-authors and co-creators of the Quadruple (Government, University, Industry and Civil Society) and Quintuple (Quadruple Innovation Helix plus Environment) Innovation Helix concepts that extend, expand and complement the Triple Innovation Helix rubric. This article starts with brief background information on N-Tuple Helices and concludes with some implications for developing and transitional economies.
\end{abstract}

Keywords Triple Helix - Quadruple and Quintuple Innovation Helix · N-Tuple Helix · Carayannis · Campbell · Developing economy · Transitional economy

The Triple Helix (TH) model of university-industry-government (UIG) relationships and its indicators have been evolving, giving rise to a new paradigm called the "N-Tuple" of Helices. Professor Elias G. Carayannis of the George Washington University and Dr. David F. J. Campbell of the University of Klagenfurt have actively studied the emergence of N-Tuple Helices and in particular the Quadruple and Quintuple Innovation Helix concepts, and therefore I have invited them to this paper-mediated interview to gain their perspective on this new paradigm with respect to developing and transitional economies.

Q 1 One of your conceptual seeds for the N-Tuple model can be traced back to 2009: "Mode 3" and "Quadruple Helix": Toward a twenty-first century fractal innovation ecosystem (Carayannis and Campbell 2009). However, many readers are not entirely

H. W. Park $(\bowtie)$

Department of Media and Communication, Yeungnam University, 214-1, Dae-dong, Gyeongsan-si, Gyeongsangbuk-do 712-749, South Korea

e-mail: hanpark@ynu.ac.kr; parkhanwoo@hotmail.com 
familiar with your new model. Please explain briefly your conceptual point of departure and development over time.

The Quadruple Helix contextualizes the TH by adding as the fourth helix "civil society" and the "media- and culture-based public." This is the understanding that additional perspectives must be added to comprehend innovation in the unfolding twenty-first century. In fact, democracy frames and changes our conditions of innovation. The TH is not really sensitive enough for this democratic additionality, whereas the Quadruple Helix reflects on this. Furthermore, the Quintuple Helix embeds the Quadruple Helix by extending this architecture of innovation to the environment and social ecology. The Mode 3 Knowledge Production Systems concept, extends, expands and complements the Mode 1 and Mode 2 Knowledge Production concepts by emphasizing the presence and impact of higher order learning (learning, learning-to-learn and learning-to-learn how to learn (see multiple books, journal articles and publications by Carayannis et al. since 1993 to date with key one (Carayannis et al. 2001)).

Q 2 The TH model of UIG relationships has been limited to a limited number of applications, including national and regional innovation systems. What limitations hinder the extension of the TH model outside innovation research? To what extent can the Quadruple Helix or N-Tuple model help address such limitations?

The Quadruple Helix brings in aspects that are thus far not included in the TH. The TH can be said to describe core processes of the knowledge economy. The Quadruple Helix is sensitive for the knowledge society and democracy. The Quintuple Helix, finally, addresses social ecology and the need for having awareness of the environmental context of society and the economy. The Quadruple Helix and the Quintuple Helix emphasize and explain why democracy and the environment need to be integrated in the wider perspective of the architecture of innovation. Without this, our understanding of innovation is constrained and not really sufficient for fully comprehending innovation and associated challenges. In short, the TH focuses on top-down government, university and industry policies and practices whereas the Quadruple Helix focuses on BOTH top-down government, university and industry policies and practices as well as bottom-up and mid-level out civil society grass-roots initiatives and other actions that help better shape, fine-tune and make more effective and efficient the government, university and industry policies and practices. The Quintuple Helix adds to the Quadruple Helix the environmental dimension to ensure that said top-down, bottom-up and mid-level out policies, practices and initiatives are indeed as smart, sustainable and inclusive as possible and meet the triple bottom line (financial, social, and environmental) hurdles criterion.

Q 3 Before the use of the TH model and its adoption by researchers became a worldwide phenomenon, empirical measurement tended to be a major issue in academia. In response to this concern, Professor Loet Leydesdorff developed the TH indicator using a Shannontype information formula for three dimensions and their combinations (Park 2013). Can we still apply this indicator to the N-Tuple model or do you suggest something new?

We are indeed working on a number of potential metrics, including information-theoretic models using entropy as a performance measure, and this indicator may be extended to models such as the Quadruple or Quintuple Helix with the right adaptation, which may need to be nontrivial, particularly in terms of the assignment of variables and the related level of significance of each. 
Q 4 You have recently tended to emphasize the importance of social and natural components for the Quadruple Helix and the Quintuple Helix, respectively. How can these dimensions interact with the traditional $\mathrm{TH}$, that is, UIG relations?

For example, there are "innovation cultures" that influence the process of innovation within academia, markets, and political systems. Innovation cultures can be communicated by media, and innovation is carried by a diverse set of actors in civil society. All these aspects and considerations are well rooted in the Quadruple Helix. Implications of the environment and of environmental needs challenge society and the economy but also act as incentives for progressing innovation such that innovation engages knowledge production and knowledge in a new balance with our ecological environments. Moreover, and per the comments to your previous questions, the social and natural considerations act as the "creative glue" for promoting smarter, more sustainable and more inclusive growth opportunities in the Knowledge Economy and Society for both developed and perhaps even more so for transitioning and emerging economies where civil society and environmental structures, infra-structures and institutions are often lacking or under-developed allowing for the accumulation of substantial negative externalities (such as pollution) and other transactional costs of growth (such as corruption) as well as impeding or even suppressing market, knowledge and network spill-over effects (positive externalities).

Q 5 Knowledge-based innovation systems may vary across countries (Kwon 2011). However, the TH model has not been extensively examined beyond Western countries (Khan and Park 2012). In what context can N-Tuple Helix relations become more important? In addition, how can we functionally and/or intellectually validate of the $\mathrm{N}$-Tuple model for developing and transitional economies?

Knowledge-based innovation may never be seen as a privilege of industrialized countries. This indeed would be a misleading approach. Knowledge-based innovations are just as valid for emerging economies and developing countries. In that sense, the Quadruple Helix and the Quintuple Helix are global und universal. The more appropriate question to ask would be what the specific implications and ramifications for knowledge-based innovation would be when applied in diverse political, economic, social, and technological contexts around the globe (Carayannis 1998a, b, 1999a, b, 2000, 2001, 2004, 2008; Carayannis et al. 2000, 2006, 2011, 2012a, b; Carayannis and Alexander 1999, 2000, 2002, 2004; Carayannis and Laget 2004; Carayannis and von Zedtwitz 2005; Carayannis 2009; Carayannis and Campbell 2009, 2012) and how it concerns developed democracies versus emerging autocracies. In particular, the Quadruple and Quintuple Innovation Helix constructs may well serve to reveal and promote ways and means to help advance growth in a manner that is becoming increasing aligned with the progress of democracy instead of having growth advancing in defiance of and for the suppression of democratic institutions. Over the medium to long term, our fundamental belief and premise is that true and transparent democracy constitutes a sine qua non for smart, sustainable and inclusive growth and this constitutes our main motivation and guide for our focus on ways and means that concepts such as the Quadruple and Quintuple Innovation Helix, can better serve architect a better tomorrow for the peoples of the world.

Acknowledgments For the further discussion on the N-Tuple Helices, please email Elias G. Carayannis at caraye@gwu.edu and David F. J. Campbell at David.Campbell@uni-klu.ac.at and David.Campbell@uniak.ac.at. 


\section{References}

Carayannis, E. (1998a). The strategic management of technological learning in project/program management: The role of extranets, intranets and intelligent agents in knowledge generation, diffusion, and leveraging. Technovation, 18(11), 697-703.

Carayannis, E. (1998b). Higher order technological learning as determinant of market success in the multimedia arena, a success story, a failure, and a question mark: Agfa/Bayer AG, Enable Software, and Sun Microsystems. Technovation, 18(10), 639-653.

Carayannis, E. (1999a). Organizational transformation and strategic learning in high risk, high complexity environments. Technovation, 19(2), 87-103.

Carayannis, E. (1999b). Knowledge transfer through technological hyperlearning in five industries. Technovation, 19(3), 141-161.

Carayannis, E. (2000). Investigation and validation of technological learning versus market performance. Technovation, 20(7), 389-400.

Carayannis, E. G. (2001). The strategic management of technological learning. Boca Raton, FL: CRC Press.

Carayannis, E. G. (2004). Measuring intangibles: Managing intangibles for tangible outcomes in research and innovation. International Journal of Nuclear Knowledge Management, 1(1/2), 49-67.

Carayannis, E. G. (2008). Knowledge-driven creative destruction, or leveraging knowledge for competitive advantage: Strategic knowledge arbitrage and serendipity as real options drivers triggered by coopetition, co-evolution and co-specialization. Industry and Higher Education, 22(6), 343-353.

Carayannis, E. G. (2009). Firm evolution dynamics: Toward sustainable entrepreneurship and robust competitiveness in the knowledge economy and society. International Journal of Innovation and Regional Development, 1(3), 235-254.

Carayannis, E., \& Alexander, J. (1999). Winning by co-opeting in strategic government-university-industry (GUI) partnerships: The power of complex, dynamic knowledge networks. Journal of Technology Transfer, 24(2/3), 197-210.

Carayannis, E. G., \& Alexander, J. (2000). Revisiting SEMATECH: Profiling public- and private-sector cooperation. Engineering Management Journal, 12(4), 33-42.

Carayannis, E. G., \& Alexander, J. (2002). Is technological learning a firm core competence; when, how, and why: A longitudinal, multi-industry study of firm technological learning and market performance. Technovation, 22(10), 625-643.

Carayannis, E. G., \& Alexander, J. (2004). Strategy, structure and performance issues of pre-competitive R\&D consortia: Insights and lessons learned from SEMATECH. IEEE Transactions of Engineering Management, 51(2), 226-232.

Carayannis, E. G., \& Campbell, D. F. J. (2009). 'Mode 3' and 'Quadruple Helix': Toward a 21st century fractal innovation ecosystem. International Journal of Technology Management, 46(3/4), 201-234.

Carayannis, E. G., \& Campbell, D. F. J. (2012). Mode 3 knowledge production in Quadruple Helix innovation systems: Twenty-first democracy, innovation, and entrepreneurship for development, Springerbriefs in business, New York, NY: Springer.

Carayannis, E. G., \& Formica, P. (2006). Intellectual venture capitalists: An emerging breed of knowledge entrepreneurs. Industry and Higher Education, 20(3), 151-156.

Carayannis, E. G., \& Laget, P. (2004). Trans-Atlantic innovation infrastructure networks: Public-private, EU-US R\&D partnerships. Journal of R\&D Management, 34(1), 17-32.

Carayannis, E. G., \& von Zedtwitz, M. (2005). Architecting gloCal (global-local), real-virtual incubator networks (G-RVINs) as catalysts and accelerators of entrepreneurship in transitioning and developing economies: Lessons learned and best practices from current development and business incubation practices. Technovation, 25(2), 95-110.

Carayannis, E., Alexander, J., \& Ioannidis, A. (2000). Leveraging knowledge, learning, and innovation in forming strategic government university industry (GUI) R\&D partnerships in the US, Germany, and France. Technovation, 20(9), 477-488.

Carayannis, E. G., Popescu, D., Sipp, C., \& Stewart, M. (2006). Technological learning for entrepreneurial development (TL4ED) in the knowledge economy (KE): Case studies and lessons learned. Technovation, 26(4), 419-443.

Carayannis, E. G., Dubina, I. N., \& Campbell, D. F. J. (2011). Creative economy and a crisis of the economy? Coevolution of knowledge, innovation, and creativity, and the knowledge economy and knowledge society. Journal of the Knowledge Economy, 3(1), 1-24.

Carayannis, E. G., Barth, T. D., \& Campbell, D. F. J. (2012a). The Quintuple Helix innovation model: Global warming as a challenge and driver for innovation. Journal of Innovation and Entrepreneurship, 1, 2. doi:10.1186/2192-5372-1-2. 
Carayannis, E. G., Pizradeh, A., \& Popescu, D. (2012b). Institutional learning and knowledge transfer across epistemic communities. Newyork, NY: Springer.

Khan, G. F., \& Park, H. W. (2012). Editorial: Triple-Helix and Innovation in Asia using scientometrics, webometrics, informetrics. Scientometrics, 90(1), 1-7 (a special issue on Triple-Helix and innovation in Asia using scientometrics, webometrics, informetrics).

Kwon, K. S. (2011). Are scientific capacities and industrial funding critical for universities' knowledge transfer activities? A case study of South Korea. Journal of Contemporary Eastern Asia, 10(1), 15-23.

Park, H. W. (2013). An interview with Loet Leydesdorff: The past, present, and future of the Triple Helix in the age of big data. Scientometrics. doi:10.1007/s11192-013-1123-4. 